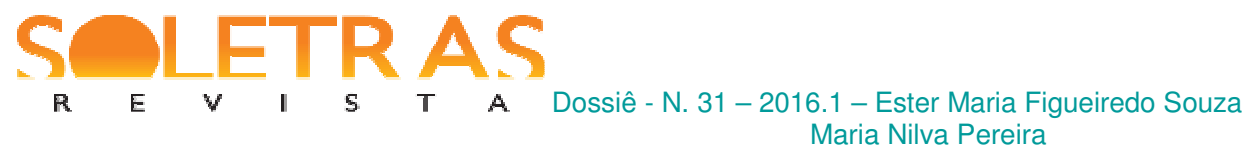

\title{
Estratégias de cortesia na interação de professora e alunos numa classe de língua portuguesa
}

\author{
Maria Nilva Pereira ${ }^{1}$ \\ Ester Maria de Figueiredo Souza ${ }^{2}$ \\ Universidade Estadual do Sudoeste da Bahia
}

Resumo: Partindo da noção da réplica bakhtiniana, assim como considerando também os conceitos de enunciado e gênero, analisa-se a interação verbal entre professora e alunos numa classe de Língua Portuguesa de uma escola da rede pública estadual, com o fito de descrever a situação discursiva, por meio da exploração dos enunciados e identificar as estratégias de (des)cortesia empregadas pelos sujeitos interactantes nessa situação concreta de diálogo. A discussão que aqui se entabula apoia-se em conceitos desenvolvidos por Bakhtin e seu Círculo, assim como nos estudos de Preti (2008) e de Kerbrat-Orecchioni (2002), quanto à definição e caracterização da cortesia e quanto aos recursos linguísticos relacionados com a sua manifestação. Os dados utilizados para este estudo são parte do corpus da pesquisa de mestrado em andamento junto ao Programa de Pós-graduação em Letras: Cultura, Educação e Linguagens da Universidade Estadual do Sudoeste da Bahia - UESB. Para a produção dos dados deste artigo, delimita-se uma aula do corpus da pesquisa, a fim de observar nos enunciados que a compõem a presença de estratégias de (des)cortesia. Os resultados apontam para a presença de enunciados que podem ser analisados como estratégias de cortesia tanto por parte da professora quanto pelos alunos, considerando, porém, que tal caracterização não pode ser definitiva, visto que os sistemas interacionais e as regras de cortesia variam de um grupo cultural para outro.

Palavras-chave: Cortesia. Gênero. Réplica.

\section{Considerações iniciais}

O espaço-tempo da sala de aula é propício para a interação de professor e alunos no intuito de construir os processos de ensino e aprendizagem, os quais se efetivam por meio da realização de atividades as mais diversas, envolvendo o uso da língua e da linguagem verbal e não verbal. Dentro desse espaço-tempo as relações são tecidas por intermédio da linguagem, valendo-se os atores do processo de enunciados completos que podem ser replicados e que são por sua vez réplicas em relação a outros enunciados anteriores. A (des)cortesia, como estratégia de manutenção de relações, está presente nesse contexto, assim como em todas as relações humanas.

1 Mestre em Letras. Pesquisadora do Grupo de Pesquisa Linguagem e Educação (GPLED/CNPq) . Tradutora. Professora educação básica.

2 Doutora em Educação. Pós-doutorado em Linguística. Professora Plena da Universidade Estadual do Sudoeste da Bahia - UESB Líder do Grupo de Pesquisa Linguagem e Educação (GPLED/CNPq). 


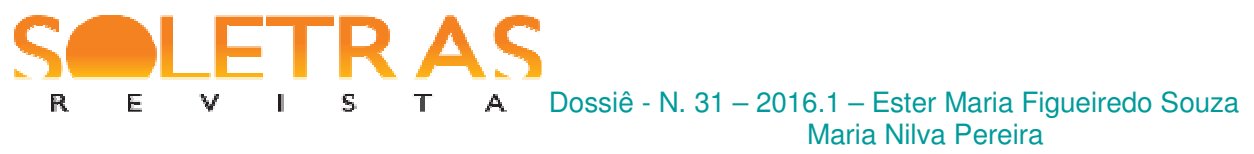

Desse modo, este artigo apresenta uma interface entre os conceitos de réplica, enunciado e gênero, oriundos das produções do Círculo de Bakhtin e estudos acerca da cortesia verbal. Para tanto, partimos de algumas contribuições fundamentais dos estudos bakhtinianos, a partir das quais definimos e caracterizamos a aula de Língua Portuguesa, para, em seguida, relacionar tais conceitos com os estudos da cortesia verbal e, finalmente, identificar, nos enunciados que compõem a aula em análise, as estratégias de cortesia utilizadas pelos sujeitos em interação.

A aula utilizada como dado para este estudo é parte do corpus da pesquisa de mestrado em andamento junto ao Programa de Pós-graduação em Letras: Cultura, Educação e Linguagens da Universidade Estadual do Sudoeste da Bahia - UESB.

\section{Partindo do Círculo de Bakhtin}

As obras provenientes do grupo de estudiosos russos que ficou conhecido como o Círculo de Bakhtin figuram entre as mais férteis inspirações para os estudos da linguagem, quer estes se concentrem em obras literárias quer se voltem para práticas linguageiras do cotidiano ou ainda das diversas esferas da produção cultural.

Valemo-nos, portanto, de conceitos desse campo de estudos como lentes através das quais olhamos para nos aproximarmos do espaço-tempo da sala de aula e selecionamos para este estudo as noções de réplica, enunciado e gênero.

Entendemos a réplica, com Bakhtin (2011), como sendo os enunciados dos interlocutores que se alternam regularmente nos diálogos. $\mathrm{O}$ acabamento da réplica expressa a posição do locutor e permite uma tomada de posição responsiva. Tal responsividade pode ser observada seja em relação ao ouvinte, seja no que se refere ao falante. A responsividade, quanto ao ouvinte, é caracterizada não só pela resposta concreta que este dá a um outro enunciado, mas inclusive pela simples compreensão que, para o autor, é uma compreensão responsiva, uma vez que ao compreender um enunciado, podemos concordar com ou discordar dele, podemos completá-lo, aplicá-lo, utilizá-lo. "Portanto, toda compreensão plena real é ativamente responsiva e não é senão uma fase inicial preparatória da resposta (seja qual for a forma em que ela se dê)" (BAKHTIN, 2011, p. 272).

Tal resposta é preparada durante o processo de escuta e compreensão do discurso de outrem, muitas vezes já a partir da primeira palavra ouvida. “Toda compreensão da fala viva, do enunciado vivo é de natureza ativamente responsiva (embora o grau desse ativismo seja

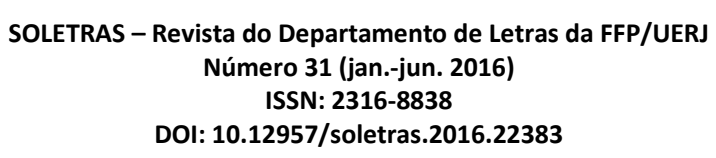




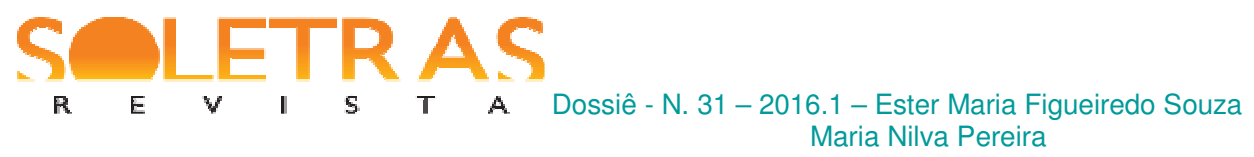

bastante diverso); toda compreensão é prenhe de resposta, e nessa ou naquela forma a gera obrigatoriamente: o ouvinte se torna falante" (BAKHTIN, 2011, p. 272). A compreensão responsiva sempre se realiza numa ação, o que pode acontecer imediatamente ou pode se dar como uma "compreensão responsiva de efeito retardado" (BAKHTIN, 2011, p. 272), isto é, aquilo que foi ouvido e compreendido mais cedo ou mais tarde surgirá nos discursos ou nas atitudes do ouvinte, sendo que a maioria dos gêneros discursivos da comunicação cultural foram concebidos exclusivamente para essa compreensão de efeito retardado.

Com relação ao falante, podemos falar também em responsividade, visto que este

[...] não é o primeiro falante, o primeiro a ter violado o eterno silêncio do universo, e pressupõe não só a existência do sistema da língua que usa mas também de alguns enunciados antecedentes - dos seus e alheios - com os quais o seu enunciado entra nessas ou naquelas relações (baseia-se neles, polemiza com eles, simplesmente os pressupõe já conhecidos do ouvinte). Cada enunciado é um elo da corrente complexamente organizada de outros enunciados (BAKHTIN, 2011, p. 272, ênfase acrescida).

Assim, todo enunciado é uma espécie de resposta a todos os outros enunciados já proferidos, seja porque retoma seu tema, ratificando-os ou polemizando com eles, seja porque é impossível falar de algo absolutamente novo, nomear pela primeira vez os objetos do mundo exterior ou interior. Tudo o que existe já foi nomeado de alguma forma e nossos enunciados respondem ao que está posto.

Segundo o autor, a relação entre as réplicas do diálogo é comparável à relação entre os enunciados completos, é uma variante desta, e só é possível entre enunciados originários de sujeitos diferentes, uma vez que pressupõe o outro membro da comunicação verbal (BAKHTIN, 2011, p. 275-6).

Nos aportamos, assim, no pensamento bakhtiniano para considerar a noção de réplica como constitutiva das estratégias de (des)cortesia. Essas réplicas nos interessam pelo seu caráter dialógico do percurso enunciativo da aula e se revozeam ao suscitar nos participantes da aula novas entonações que se qualificam pela intenção dos sujeitos de expor os seus enunciados. Essa persppectiva por nós assumida, nos incita a referenciar Farraco, quando argumenta que "Compreender não é um ato passivo, mas uma réplica ativa, uma resposta, uma tomada de posição diante do texto" (FARACO, 2009, p. 42).

Desse modo, segundo o filósofo russo,

[...] a alternância dos sujeitos do discurso, que emoldura o enunciado e cria para ele a massa firme, rigorosamente delimitada dos outros enunciados a ele vinculados, é a primeira peculiaridade constitutiva do enunciado como 


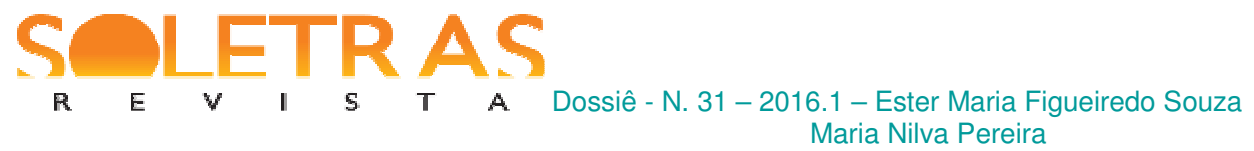

unidade da comunicação discursiva, que o distingue da unidade da língua [a oração] (BAKHTIN, 2011, p. 279-80).

Temos, então, além dessa "alternância dos sujeitos do discurso", a segunda peculiaridade que constitui o enunciado, e que está "intimamente vinculada à primeira, [...] a conclusibilidade específica do enunciado" (BAKHTIN, 2011, p. 280). Esse caráter conclusivo do enunciado é "uma espécie de aspecto interno da alternância dos sujeitos do discurso", alternância que "pode ocorrer precisamente porque o falante disse (ou escreveu) tudo o que quis dizer em dado momento ou sob dadas condições. Quando ouvimos ou vemos, percebemos nitidamente o fim do enunciado, como se ouvíssemos o 'dixi' conclusivo do falante" (BAKHTIN, 2011, p. 280, grifo do autor). Assim, a alternância dos sujeitos e a conclusibilidade do enunciado permitem identificar essa unidade da comunicação discursiva.

Quanto à conclusibilidade do enunciado, afirma Bakhtin (2011, p. 280) que o seu primeiro e mais importante critério é a possibilidade de responder a ele, de assumir em relação a ele uma posição responsiva. Esta pode se dar por meio de uma réplica propriamente dita, por meio de uma ação (caso o enunciado seja uma ordem ou pedido), ou ainda por meio de uma compreensão ou avaliação (como no caso de um romance ou obra de arte). São três os elementos que determinam a conclusibilidade do enunciado, a qual garante a possibilidade de resposta ou de compreensão responsiva: “1) exauribilidade do objeto e do sentido; 2) projeto de discurso ou vontade de discurso do falante; 3) formas típicas composicionais e de gênero do acabamento" (BAKHTIN, 2011, p. 281).

Segundo o autor, "a exauribilidade semântico-objetal do tema do enunciado" (BAKHTIN, 2011, p. 281) é diversa nos diferentes campos da comunicação discursiva. Existe a exauribilidade plena em alguns campos, como perguntas e respostas factuais, pedidos, ordens, em alguns campos oficiais, ordens militares etc., ou seja, em campos nos quais os gêneros do discurso possuem uma natureza padronizada e dos quais está praticamente ausente a criatividade. Já nos campos da criação, de modo especial no científico, a exauribilidade é muito relativa, vale dizer, aqui existe "um mínimo de acabamento, que permite ocupar uma posição responsiva" (BAKHTIN, 2011, p. 281).

Esse acabamento, nesses casos dos campos da criação, está intimamente relacionado ao segundo elemento citado anteriormente, ou seja, o projeto de dizer do falante. É possível perceber, em cada enunciado - das réplicas do cotidiano às grandes obras de ciência ou literatura -, a intenção discursiva do falante a determinar o todo do enunciado, seu volume e suas fronteiras. Essa vontade de dizer determina tanto a escolha do objeto quanto seus limites

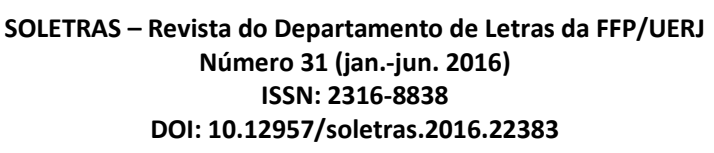




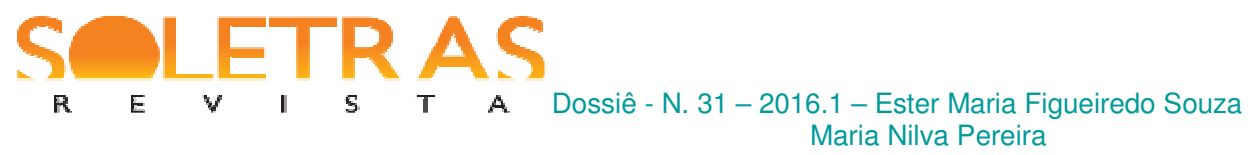

e sua exauribilidade, assim como determina, também, a seleção da forma do gênero no qual o enunciado será construído, isto é, o terceiro elemento acima citado, que Bakhtin considera o mais importante, "as formas estáveis de gênero do enunciado" (BAKHTIN, 2011, p. 282, grifo do autor). Ele afirma que "a vontade discursiva do falante se realiza antes de tudo na escolha de um certo gênero do discurso" (p. 282, grifos do autor).

De acordo com o filósofo russo, o conceito de gêneros do discurso está interrelacionado ao de enunciado, uma vez que define os gêneros como "tipos relativamente estáveis de enunciados" (BAKHTIN, 2011, p. 262, grifo do autor) e afirma que cada esfera de utilização da língua elabora seus enunciados relativamente estáveis aos quais chamamos gêneros do discurso. Em seguida, trata da extrema heterogeneidade dos gêneros do discurso, da qual advém a dificuldade em definir a natureza geral do enunciado e destaca a classificação dos gêneros discursivos como primários e secundários. Os gêneros primários, ditos simples, abrangem as comunicações da vida cotidiana, enquanto os secundários, que ele define como complexos, figuram em circunstâncias de comunicação cultural mais complexa e preponderantemente escrita, como uma comunicação artística, científica ou sociopolítica. Os gêneros secundários podem absorver no seu interior gêneros primários, como, por exemplo, uma réplica de um diálogo cotidiano inserida num romance. Nesse caso, o gênero primário se transforma, perdendo sua relação com a realidade existente e ganhando significado apenas dentro do gênero secundário, ou seja, considerando o exemplo citado, a réplica do diálogo cotidiano só se integra à realidade por meio do romance concebido como fenômeno da vida artístico-literária e não da vida cotidiana.

Souza (2012, p. 74), ao abordar a compreensão da aula como uma prática discursiva, nos indica, sob o pano de fundo da teoria dialógica da linguagem, a necessidade de reconhecer as fronteiras dos enunciados para se facultar os processos de interação verbal entre os sujeitos. Para tanto, ratifica que a réplica é ação responsiva no contexto da sala de aula.

Essas retomadas dos conceitos de réplica, enunciado e gênero permitem-nos realizar uma leitura dos enunciados da aula identificando aí os aspectos da teoria que possibilitam a sua classificação como um enunciado $\mathrm{e}(\mathrm{m})$ um gênero discursivo, destacando as várias réplicas dos sujeitos que se alternam regularmente na interação. Tais réplicas apresentam aspectos que podem ser considerados como estratégias de (des)cortesia, da qual passaremos a tratar.

Assumindo que organizamos nossa comunicação por meio de domínio discursivos dos gêneros, na sala de aula, as possibilidades de se estabelecer interações de cortesia pode ser

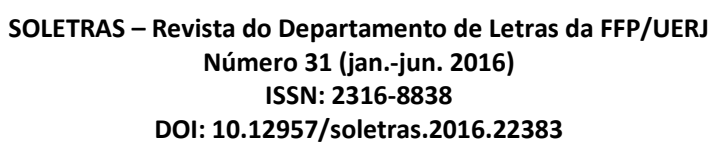




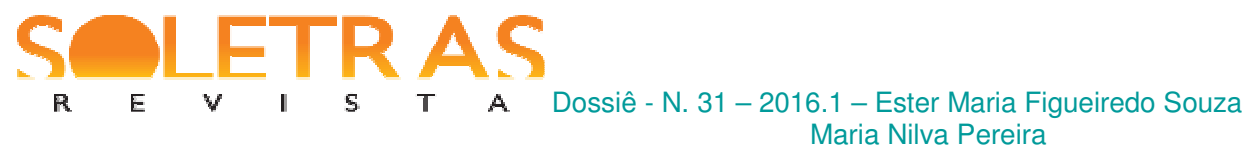

manifestada de maneiras distintas. Essa manifestação é tomada por nós como uma réplica a um enunciado ou a enunciados produzidos pelos sujeitos nos papéis institucionais de professor e aluno. No intercurso do diálogo deste texto, retomamos Bakhtin:

Um membro de um grupo falante nunca encontra previamente a palavra como palavra neutra da língua, isenta das aspirações e avaliações de outros ou despovoada das vozes dos outros. Absolutamente. A palavra, ele a recebe da voz de outro e repleta de voz de outro. No contexto dele, a palavra deriva de outro contexto, é impregnada de elucidações de outros (BAKHTIN, 2002, p.203).

No papel de professor podemos ignorar os enunciados replicantes dos alunos, por não valorizar essa atitude em relação ao enfoque da aula, já que os sentidos produzidos em sala de aula são confromados ao enfoque da própria aula. Porém, não há como controlar todos os processos compreensivos que ecoam nas diferentes vozes da sala de aula visto que os cenários de interação discursiva são carregados de iniciativas individuais de cada sujeito que participa desse processo.

\section{A propósito da (des) cortesia}

Entendemos, com Kerbrat-Orecchioni (2002), que a cortesia é universal e, ao mesmo tempo, não universal, vale dizer:

A cortesia é universal: em todas as sociedades humanas, sejam elas "tribos selvagens" ou "salões europeus" (Malinowski), constata-se a existência de processos de cortesia (ou técnicas de "polimento") que permitem manter entre os interactantes um mínimo de harmonia, apesar dos riscos de conflitos inerentes a qualquer interação [...]: é na medida em que se admite que qualquer encontro social é "de risco" para os atores nele envolvidos (risco por eles se sentirem ameaçados, envergonhados ou humilhados) que se deve reconhecer correspondentemente a necessidade universal desses mecanismos compensatórios que são os rituais de cortesia.

Ao mesmo tempo, porém, a cortesia não é universal, na medida em que as suas formas e condições de aplicação (quem deve ser educado, em relação a quem, como, em que circunstâncias e situação comunicativa?) variam significativamente de uma sociedade para outra. (KERBRATORECCHIONI, 2002, p. 1$)^{3}$.

3 La politesse est universelle : dans toutes les sociétés humaines, qu'il s'agisse de "tribus sauvages" ou de "salons européens" (Malinowski), on constate l'existence de procédés de politesse (ou techniques de "polissage") qui permettent de maintenir entre les interactants un minimum d'harmonie, malgré les risques de conflits inhérents à toute interaction [...] : c'est dans la mesure où l'on admet que toute rencontre sociale est "risquée" pour les acteurs qui s'y trouvent engagés (risque pour eux de se sentir menacés, embarrassés ou humiliés) que l'on doit corrélativement admettre l'universelle nécessité de ces mécanismes compensatoires que sont les rituels de politesse. 
$\mathrm{O}$ fato de os rituais de cortesia estarem presentes em todas as sociedades e variarem nas formas e condições de aplicação de uma sociedade a outra - ou seja, o que é cortês numa sociedade ou grupo cultural pode ser considerado descortês em outro grupo ou sociedade configura o aspecto normativo do fenômeno da cortesia. Como afirma Leite (2008, p. 65), "[...] embora mudem os fatos considerados corteses/descorteses, a ideia fundamental da cortesia - aquela da existência de comportamentos coletivos que permitem a melhor convivência social, a harmonia - persiste tempos afora". Assim, em todas as sociedades é possível observar a presença de certas normas de cortesia que devem ser seguidas a fim de se construir relações sociais que prezem a harmonia e a convivência cidadã.

Desse modo, a cortesia pode ser compreendida como estratégia de aproximação do outro, isto é, o eu se afasta do seu discurso para se aproximar ou não se afastar do outro, o tu. Tal aproximação pode ter, porém, objetivos variados - podemos nos aproximar do outro utilizando rituais de cortesia com o intuito somente de sermos corteses assim como podemos valer-nos de estratégias de cortesia com o propósito de obter alguma vantagem, quer seja a realização de um pedido, quer seja a criação de uma imagem positiva diante do nosso interlocutor, como afirma $\mathrm{Briz}^{4}$ (2014): "O bien me acerco al otro con fin cortés o bien me acerco al otro cortésmente como estrategia para lograr otro fin".

Caracteriza-se, desse modo, a cortesia funcional ou estratégica. A cortesia funcional apresenta um alto grau de ritualização e é inspirada por alguma norma de conduta social e/ou cultural. Nesse caso, a pessoa é simplesmente cortês. A cortesia chamada estratégica, por seu turno, é aquela utilizada com o intuito de obter outro objetivo diferente do ser cortês. As estratégias de cortesia, então, funcionam como estratégia conversacional, de manipulação.

Revisando o modelo de cortesia de Brown e Levinson, Kerbrat-Orecchioni (2002) afirma que este é baseado nas noções de "território" e de "face", rebatizadas pelos teóricos de "face negativa" e "face positiva", o que lhes permitiu construir a noção de "ato ameaçador para a(s) face(s)" (Face threatening act ou FTA). De acordo com essa perspectiva, a maioria dos atos de linguagem praticados são potencialmente ameaçadores para uma ou outra das

Mais en même temps, la politesse n'est pas universelle, dans la mesure où ses formes et ses conditions d'application (qui doit être poli, envers qui, et de quelle manière, dans telle ou telle circonstance et situation communicative ?) varient sensiblement d'une société à l'autre (A tradução das citações em língua estrangeira é de nossa responsabilidade).

4 Prof. Dr. Antonio Briz, falando sobre Cortesia y coloquialidad na conferência de abertura do II Congresso Internacional Interdisciplinar (Des)cortesia: expressão de cultura(s)?, na Universidade Cruzeiro do Sul, campus Anália Franco, São Paulo - SP, em 02 Dez. 2014. 


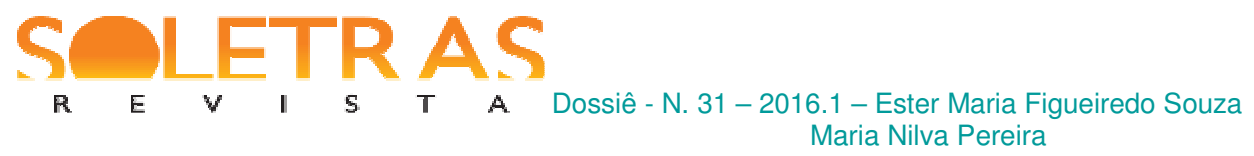

faces envolvidas, o que cria um sério risco para o bom desenrolar da interação. Intervém, nesse caso, o face-work, expressão cunhada por Goffman (1974, apud KERBRATORECCHIONI, 2002, p. 3) para se referir a tudo o que uma pessoa faz a fim de que suas ações não prejudiquem a face de ninguém (inclusive a própria). É esse trabalho de face que Brown e Levinson chamam com o nome de cortesia.

Kerbrat-Orecchioni critica, porém, a teoria de Brown e Levinson, aquela que chama de uma concepção excessivamente pessimista da interação e afirma que, embora haja realmente atos de linguagem que são potencialmente ameaçadores para as faces dos interlocutores, há também os atos que são valorizadores dessas faces e que são vistos por Brown e Levinson como FTAs para a face negativa do destinatário. Segundo a autora, se as faces devem ser preservadas, elas pedem também gratificações mais positivas, sendo, portanto, indispensável, prever no modelo teórico um lugar para esses atos que são de certo modo o aspecto positivo dos FTAs, atos valorizadores da face do destinatário, que ela chama de FFAs (Face Flattering Acts).

Desse modo, os atos de linguagem podem ser descritos como um FTA, um FFA ou uma mistura dos dois. É possível também, segundo a autora, distinguir duas formas de cortesia: a cortesia negativa, que consiste em evitar a produção de um FTA ou atenuar sua realização; e a cortesia positiva, que consiste na realização de um FFA. E a interação é vista sob essa perspectiva como uma tentativa de equilíbrio entre FTAs e FFAs.

\section{Uma breve análise acerca de recursos linguísticos relacionados com a manifestação da cortesia}

Para a geração e análise de dados recorremos ao contexto já conhecido de uma escola pública. Trata-se de uma escola que oferta a educação básica nos segmentos de ensino fundamental e médio. Na oferta em diferentes turmas, selecionamos duas turmas do $2^{\circ}$ ano do ensino médio, sob responsabilidade de uma mesma professora, para incursionar pelos cenários de observação e análise das interações verbais, sendo uma no turno matutino e outra no vespertino. No turno matutino, as carteiras estão enfileiradas, embora não respeitando filas perfeitas. A turma que ocupa a sala é formada por trinta e nove alunos e alguns sentam-se bem próximos, formando grupos de acordo com as relações de amizade desenvolvidas. No turno vespertino, a organização das carteiras é mais livre, uma vez que, embora haja quase o mesmo número de alunos (trinta e oito matriculados) há espaço suficiente para que os alunos

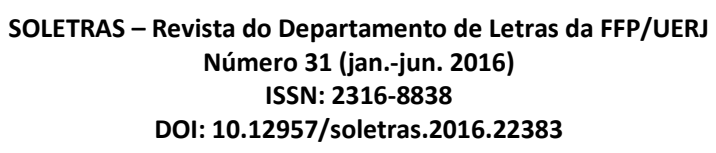




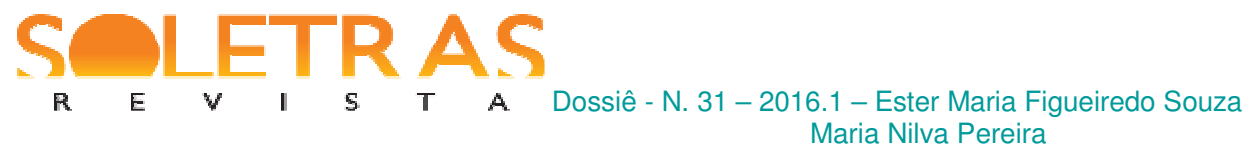

se posicionem a seu gosto, já que nem todos frequentam. Além da diferença quanto ao número de alunos, sua origem também é diversa: no turno matutino, os alunos são, na sua maioria, residentes nos diversos bairros da cidade, enquanto no vespertino quase todos são moradores da zona rural e para frequentar as aulas dirigem-se diariamente à sede do município utilizando o transporte escolar. Cada turma tem três aulas de Língua Portuguesa e Literatura Brasileira (LPLB) por semana com duração de 50 (cinquenta) minutos, com início e final marcados pelo toque de uma sirene.

Neste artigo relacionamos conceitos bakhtinianos com os estudos acerca da cortesia linguística na análise de uma aula de Língua Portuguesa, com o objetivo de localizar as estratégias de cortesia utilizadas no enunciado da aula pelos sujeitos que aí interagem nos papéis sociais de professor e aluno. Assim, ressaltamos a noção de dialogismo presente no pensamento bakhtiniano na sua aplicação para a análise em reunião de corpus de discursos produzidos nas interações didáticas na sala de aula. Essa nossa intenção converge para a afirmação de que ao se enunciar os sujeitos revelam posturas autorais, pois os enunciados são valorados quando revelam quem os pronunciou e, em decorrência, personificam ações com a linguagem que podem ser analisadas sob o enfoque das estratégias de polidez

Todo enunciado tem uma espécie de autor, que no próprio enunciado escutamos como seu criador. Podemos não saber absolutamente nada sobre o autor real, como ele existe fora do enunciado. As formas dessa autoria real podem ser muito diversas. Uma obra qualquer pode ser produto de um trabalho de equipe, pode ser interpretada como um trabalho hereditário de várias gerações, etc., e apesar de tudo, sentimos nela uma vontade criativa única, uma posição determinada diante da qual se pode reagir dialogicamente. A reação dialógica personifica toda enunciação à qual ela reage. As relações dialógicas são possíveis não apenas entre enunciações integrais (relativamente), mas o enfoque dialógico é possível a qualquer parte significante do enunciado, inclusive a uma palavra isolada, caso esta não seja interpretada como palavra impessoal da língua, mas como signo de posição semântica de um outro, como representante do enunciado de um outro, ou seja, se ouvimos nela a voz do outro (BAKHTIN, 2002, p. 184).

Observamos alguns indícios da utilização da cortesia verbal tantos nos enunciados dos alunos quanto nos da professora, destacando que, provavelmente por se tratar de uma aula expositiva, em que a professora utiliza um maior número de turnos de fala (ou réplicas, para usar um termo que nos reporta a Bakhtin), é também maior a presença de estratégias de cortesia nos seus enunciados.

Outra reflexão possível para explicar uma maior utilização de estratégias de cortesia por parte da professora refere-se ao fato de esta deter um maior poder na situação social de interação na sala de aula, como afirmam Villaça e Bentes (2008, p. 36-7): "A nosso ver, a

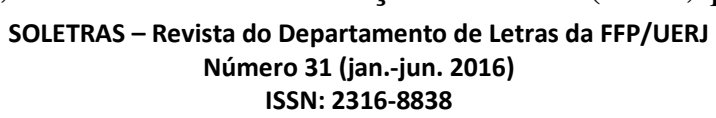

DOI: $10.12957 /$ soletras.2016.22383 
cortesia está também relacionada ao status social do locutor, quando este detém o poder de praticar determinadas ações, (como, por exemplo, a de interromper a fala de alguém) e o faz com cuidado, procurando disfarçar, atenuar o exercício desse poder”. Esse contexto é provocador de cenários discursivos que modalizam os recursos de cortesia "funcionam como formas de atenuação de atos de poder no curso da interação verbal" (VILLAÇA; BENTES, 2008, p. 36). Há uma variedade de marcas linguísticas, entre as quais figuram os marcadores de atenuação (cf. ROSA, 1992), através das quais pode-se manifestar a cortesia. Apresentamos, a seguir, os recursos linguísticos utilizados para a manifestação da cortesia que puderam ser identificados no corpus da pesquisa de que trata este artigo.

Formas verbais - (1) "Professora - então... de antemão eu gostaria de falar pra vocês que eu sempre trabalho eh usando também letras musicais inclusive a semana que vem eu gostaria que vocês providenciassem a música Aquarela de Toquinho".

Nesse fragmento temos um exemplo claro de como é possível atenuar atos de poder na interação verbal quando observamos que a professora, autoridade institucionalmente constituída na sala de aula, que poderia se dirigir aos alunos dando uma ordem direta não o faz. Ao invés disso, vale-se de formas verbais que atenuam o que deveria ser a ordem e o que efetivamente diz soa como pedido, sugestão, oportunidade para que os alunos façam algo para agradá-la: ela diz "gostaria que vocês providenciassem a música Aquarela de Toquinho", quando poderia simplesmente ter ordenado "Tragam a música Aquarela de Toquinho na próxima aula".

Uso de diminutivos - (2) "Professora - [...] então nós como professores estávamos assim refletindo um pouquinho a respeito disso né porque vocês são jovens estudantes são né eh: adolescentes e muitas vezes têm que pensar um pouquinho nas ações [...]”.

(3) "Professora - [...] isso aqui que eu tou colocando aqui é pra deixar um esquemazinho pra reconhecimento e pra lembrar e refletir um pouquinho sobre o substantivo que vai aparecer dentro da letra da música Aquarela...”.

Aqui a utilização de diminutivos suaviza o contraste entre a reflexão dos professores e a falta de reflexão dos alunos; estes têm, segundo a professora, de "pensar um pouquinho" nas suas ações. Já no exemplo (3), acima, depois de ter feito no quadro um esquema para explicar a análise morfossintática de uma oração, a professora diz que se trata de um "esquemazinho" para auxiliar os alunos a se lembrarem dos conteúdos gramaticais estudados nos anos anteriores e facilitar a análise que farão da letra da música na aula seguinte. 


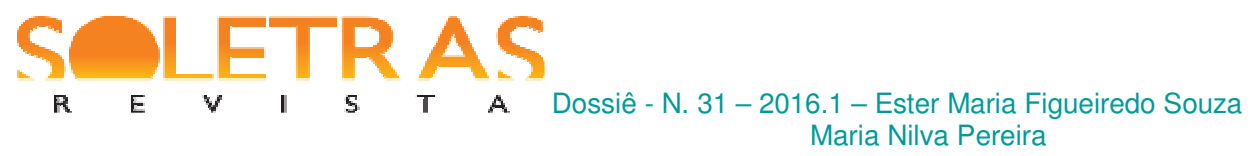

Verbos modais: acho, creio, imagino, penso etc. - (4) “Ana - [...] sabe assim eu acho que as pessoas que estão falando mal dela que acharam/ que acham que isso é errado tão fazendo pior ainda de/ dene/ denegrindo".

(5) "Professora - então assim eu acho que tem que ter um conhecimento amplo né de livro de leitura".

Nos exemplos (4) e (5) a aluna que chamamos de Ana e a professora utilizam ambas o mesmo verbo para atenuar a própria afirmação e expressá-la como uma mera opinião que pode, portanto, ser facilmente refutada. O caso da afirmação da professora é mais emblemático, porque, depois de ter citado exemplos de questões de prova do Enem em que figuraram romances variados que ela havia indicado para leitura pelos alunos, ela afirma a necessidade de os alunos ampliarem seu conhecimento de leitura não como um fato comprovado, mas como uma opinião pessoal. Nesse caso, está claro que não se trata de opinião: o aluno que quiser ser bem sucedido nos exames precisa ler muito, mas a professora não o afirma categoricamente, atenua sua afirmação com o modal acho.

Enunciados justificativos ou explicativos - (6) "Professora - olha, preste atenção o que eu/ eu toquei no assunto aqui porque também não precisa essa questão de você ignorar a situação... vocês são meus alunos né aconteceu isso na escola a gente tem que tenta:r é conversar pra chegar a uma coisa comprovada... não é pra inflamar ninguém nem pra gerar novos conflitos não é pra gerar novos (procedimentos) não pelo contrário é pra tentar... né controlar...".

No exemplo (6) acima, a professora justifica o fato de ter introduzido com os alunos uma conversa acerca de uma briga ocorrida na escola no dia anterior. Trata-se de um assunto desagradável que ela talvez preferisse ter evitado, mas cuja abordagem se justifica pelo fato de eles serem seus alunos e, portanto, ela considerar que não deveria ignorar a situação, mas, ao contrário, orientá-los sobre a melhor maneira de agir na gestão dos conflitos e evitar que estes alcancem grandes proporções.

Consideramos que a interação verbal na sala de aula rege-se predominantemente pelo padrão assimétrico dos papéis discursivos de professor e aluno. Em outras palavras, a interação professor/aluno, caracterizada como uma relação assimétrica, visto que

[...] a iniciativa interacional está na voz do professor, indica o poder que este tem ao controlar o significado e, por extensão, as identidades sociais dos alunos, tanto como identidade de aluno (o papel institucional), como outras identidades sociais revivenciadas em classe (MOITA LOPES, 2001, p. 325). 


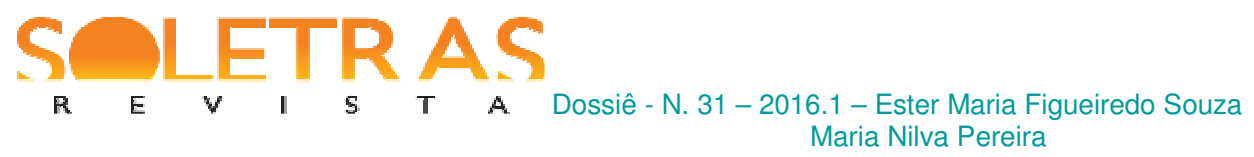

A ruptura desse padrão na sala de aula é plausível de ocorrência, tanto quanto se modalizam as estratégias de cortesia presentes nos espaços discursivos das enunciações do professor $(\mathrm{a} / \mathrm{s})$ e aluno $(\mathrm{a} / \mathrm{s})$.

\section{Considerações finais}

Consideramos de extrema importância o realçar a natureza dos processos interacionais para que seja tematizada tal abordagem para e na formação de professores Os discursos da aula modalizam-se e se constituem como linguagem, produto de um gênero. Esses organizam atividade humana e comuicação e, nós, como sujeitos de linguagem, dispomos de um repertório inesgotável de combinações para produzir ações com e sobre a linguagem, gerar novos gêneros e enunciar os que já conhecemos. Em outras palavras, não se trata de listar expressões a serem utilizadas para denotar cortesia ou descortesia, mas propiciar a compreensão por parte do aluno de como a cortesia funciona nas relações sociais, a fim de que ele possa utilizá-la nas interações de que participa dentro e fora da escola, contribuindo para a criação e manutenção de relações fundadas em valores como cidadania, respeito e convivência pacífica.

Uma reflexão que se volta para abordagens interacionais de análise do discurso didático e da formação de professores, levando em consideração esses pressupostos, terá, pois, que se voltar para a compreensão e valorização das relações que se estabelecem entre sujeitos nas práticas sociais, portanto, aportada na concepção interacionista da linguagem. Assim, propõe-se que o professor exerça sua autonomia docente e perspective acolher as enunciações dos alunos por meio do reconhecimento do direito de dizer na sala de aula, do enunciar-se como Ser de linguagem para que se instaurem práticas de ensino o trabalho de ações com a linguagem, como mecanismos de constituição de alteridades e identidades sociais, revelando-se a dimensão estética da sala de aula para a formação humana. Nesse prisma, abdica-se da centralidade do ensino na seleção e exposição de conteúdos didáticos para se explorar discursivamente temas que sejam e estejam inseridos na realidade de interação verbal.

Nosso movimento teórico neste texto foi o de estabelecer contornos entre conceitos bakhtinianos, em especial o de réplica, com estudos da cortesia linguística com o fito de realçar possibilidades de entrecruzamentos teóricos entre os dois campos de estudos e, como tal, reiteramos a importância de se verticalizar abordagens complementares para tipificar e 


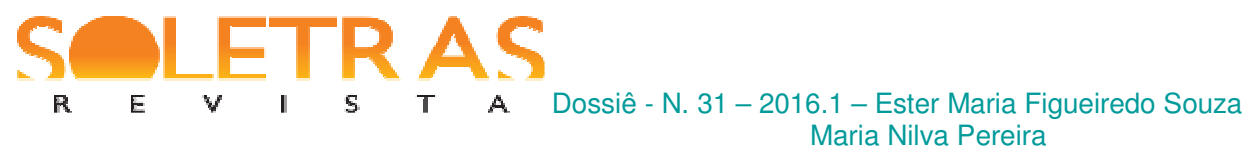

revelar a densidade dos processos de interação verbal nos e dos limites da aula como gênero discursivo.

\section{Referências}

BAKHTIN, M. Problemas da Poética de Dostoiévski. Rio de Janeiro, Ed. Forense Universitária, 2002.

BAKHTIN, M. Estética da criação verbal. Trad. Paulo Bezerra. 6. ed. São Paulo: WMF Martins Fontes, 2011.

BRIZ, A. Cortesía y coloquialidad. Conferência de abertura. II Congresso Internacional Interdisciplinar (Des) cortesia: expressão de cultura(s)? São Paulo: Universidade Cruzeiro do Sul. 02 a 05 Dez. 2014.

FARACO, C. A. Linguagem \& Diálogo: as ideias linguísticas do círculo de Bakhtin. São Paulo: Parábola Editorial, 2009.

KERBRAT-ORECCHIONI, C. Politesse en deçà des Pyrénées, impolitesse au-delà : retour sur la question de l'universalité de la (théorie de la) politesse. Marges linguistiques. Université Lumière Lyon 2. Mai. 2002. Disponível em <http://icar.univlyon2.fr/Equipe1/documents/MargesKerbrat.pdf> Acesso em 17 Nov. 2014.

LEITE, M. Q. Cortesia e descortesia: a questão da normatividade. In: PRETI, Dino (Org.) Cortesia verbal. São Paulo: Humanitas, 2008. p. 49-87.

MOITA LOPES, Luiz Paulo da. Discursos de identidade em sala de aula de leitura de L1: a construção da diferença. In: SIGNORINI, Inês (Org.). Lingua(gem) e identidade: elementos para uma discussão no campo aplicado. Campinas, SP: Mercado de Letras; São Paulo: Fapesp, 2001. p. 303-30.

PRETI, D. (Org.). Cortesia verbal. São Paulo: Humanitas, 2008.

SOUZA, Ester Maria de Figueiredo. Indagações acerca do enunciado concreto em Mikhail Bakhtin e o gênero do discurso aula. In: SANTOS, Elmo (Org.). Transdiscursividades: linguagem, teorias e análises. Salvador: EDUFBA, 2012. p. 65-87.

VILLAÇA, I. G.; BENTES, A.C. Aspectos da cortesia na interação face-a-face. In: PRETI, Dino (Org.) Cortesia verbal. São Paulo: Humanitas, 2008. p. 19-48.

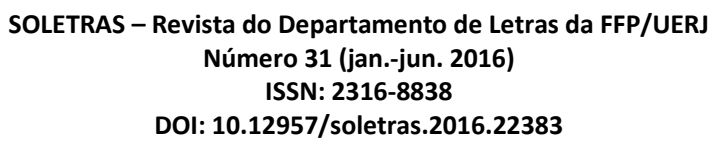




\begin{abstract}
Following the concept of Bakhtin's reply, also considering the concepts of statement and gender. We analyze the verbal interaction between teacher and students in a class of Portuguese Language of a state public school, with the aim of describing the discourse situation, through exploration of the statements and identifying (im)politeness strategies employed by interactants at this particular dialogue situation. This discussion leans on concepts developed by Bakhtin and his Circle, as well as on studies realized by Preti (2008) and Kerbrat-Orecchioni (2004), in order to define and characterize the politeness and the language resources related to politeness manifestation. The data used for this paper are part of the corpus of the master's research in progress by the Programa de Pós-Graduação em Letras: Cultura, Educação e Linguagens at Universidade Estadual do Sudoeste da Bahia $U E S B$. To produce the data for this article we delimited a class of the research corpus, in order to observe in its statements the presence of (im)politeness strategies. The results show the presence of statements that can be analyzed as politeness strategies by both the teacher and the students. We have to consider, however, that this characterization cannot be definitive, since the interactional systems as well as the politeness rules vary from one cultural group to another.
\end{abstract}

Keywords: Politeness. Gender. Replica.

Recebido em: 08 de abril de 2016.

Aprovado em: 27 de junho de 2016. 